Individual Development Plans (IDPs): An underutilized advising tool in the geosciences Supplemental Data

Deborah E. Eason ${ }^{1 *}$, Barbara C. Bruno ${ }^{2}$, Daniela Böttjer-Wilson ${ }^{3}$

* Corresponding author

${ }^{1}$ Department of Earth Sciences, University of Hawai'i at Mānoa, Honolulu, HI 96822, USA (phone: 808956-4634; email: deborahe@hawaii.edu)

${ }^{2}$ Hawai' $i$ Institute of Geophysics and Planetology, University of Hawai'i at Mānoa, Honolulu, HI 96822

${ }^{3}$ Center for Teaching Excellence, University of Hawai'i a at Mānoa, Honolulu, HI 96822

In this supplemental data file, we include additional program information and implementation details, advisor/mentor survey results, and a copy of the basic IDP template used in the 'Ike Wai project.

\title{
About the program
}

The 'Ike Wai project requires IDPs for all Graduate Scholars and Postdoc Scholars as part of a broader professional development program that also includes cohorted training in a variety of professional skills. Graduate Scholars can devote up to $20 \%$ of their graduate assistantship on career development activities. The project has included 19 Graduate Scholars to date, each matched with a research advisor and professional development (PD) mentor. While some research advisors have more than one advisee, all PD mentors have only one mentee. Due to the small population size, we did not collect demographic data as part of this survey in order to help preserve anonymity. However, based on the most recent project demographics, the 2019 Graduate Scholars were $\sim 57 \%$ women and 43\% underrepresented minorities, including 21\% Native Hawaiian or Pacific Islander.

\section{Survey of Advisors/Mentors}

In addition to the graduate student survey, we conducted an anonymous survey of research advisors and $\mathrm{PD}$ mentors in our program, asking them to report on the perceived effectiveness of IDPs (Fig. S1) and the typical time spent with students in a given term (Fig. S2). Results suggest that IDPs are overwhelmingly popular among advisors and PD mentors, with $81 \%$ saying they would recommend IDPs to other advisors/mentors, and are regarded as effective tools while requiring relatively little time from advisors and PD mentors. 


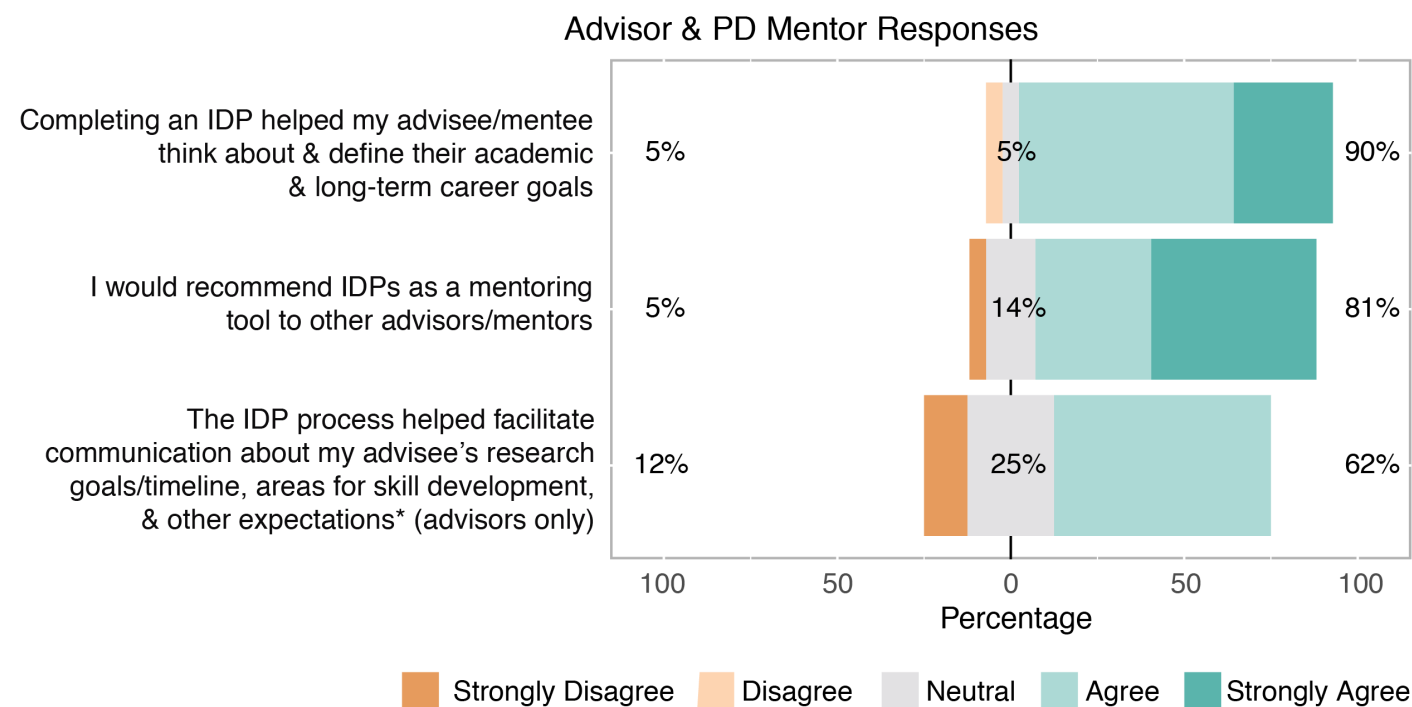

Figure S1: Results from anonymous survey of research advisors and PD mentors $(\mathrm{n}=21)$.

Percentages shown correspond to the total responses for disagree or strongly disagree (left), neutral (center), and agree or strongly agree (right).

Figure S2: Average meeting frequency, duration, and time spent specifically on IDPs, as report by research advisors and PD mentors (anonymous survey, $\mathrm{n}=21$ ).
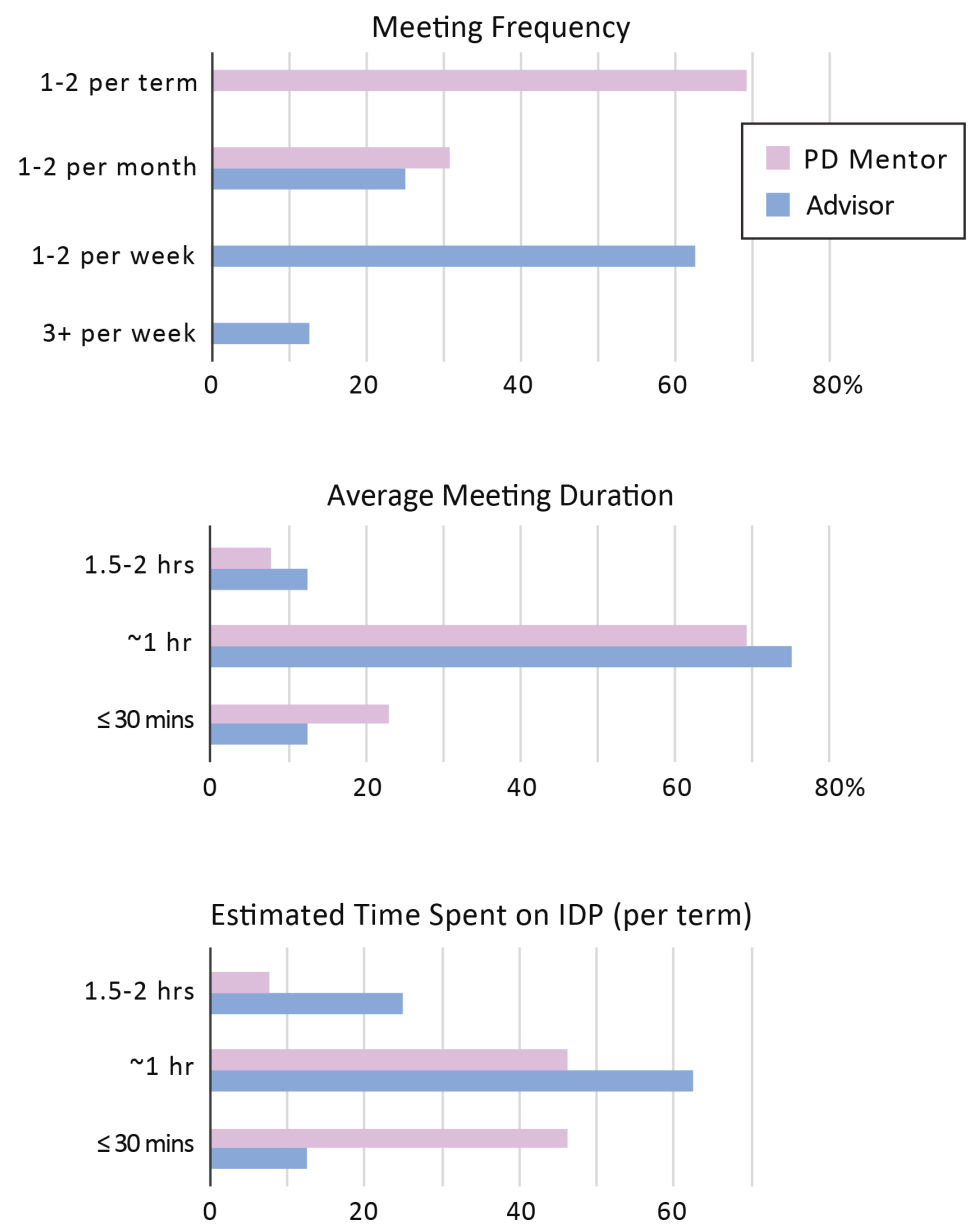


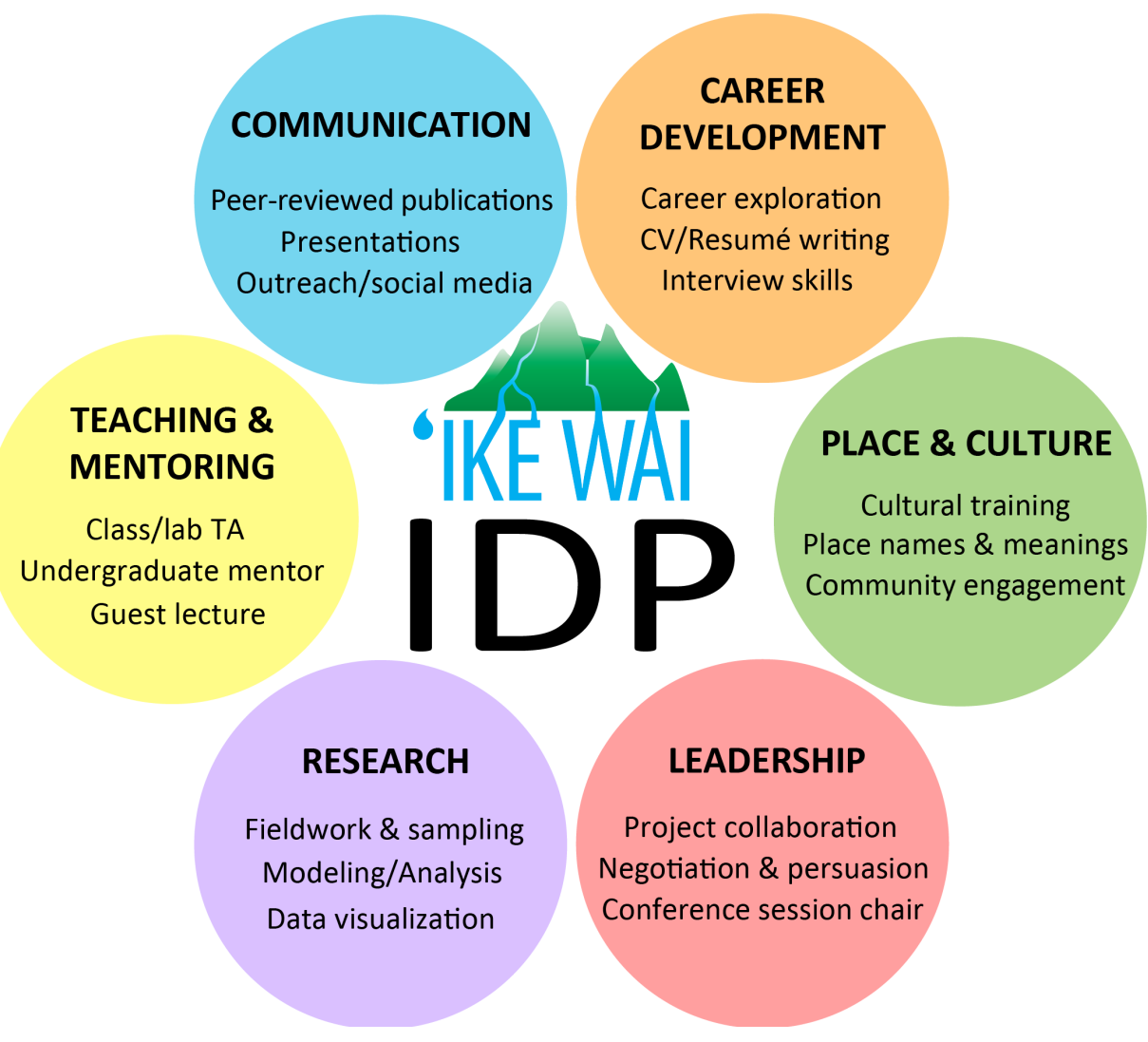

Figure S3. The six core competencies (bold) in 'Ike Wai's Individual Development Plan (IDP), with a few examples listed for each area. Students complete a self-assessment in each area and develop an action plan based on their individual priorities.

Figure S4. The IDP template used on the project (attached), including instructions, selfassessment (Form 1), the action plan (or IDP) (Form 2), and signature form (Form 3). Additional notes on implementation: In practice, we have adopted more flexibility with the meeting order to help keep the process moving along (especially when faculty may be unavailable due to field work or other travel constraints). In addition, our IDP Coordinator almost always meets with students one-on-one (vs. with their advisors/mentors present), which greatly simplifies scheduling and seems to be universally preferred by the students. 


\section{Individual Development Plan: Guidelines for 'Ike Wai Graduate Students \& Post-Docs}

\section{Summary of forms:}

- Form 1 (Self-Assessment)

- Form 2 (Individual Development Plan)

- Form 3 (Cover Sheet)

\section{Rationale}

Our overarching goal is for graduate students and post-docs to emerge from their 'Ike Wai training period competitive (via an intentional professional development program), committed to interdisciplinary research ('Ike Wai projects will transcend disciplinary boundaries), inclusive (comfortable with diversity and culturally adept), and integral (comprehensively networked with stakeholders and career development opportunities). 'Ike Wai graduate students and post-docs are expected to spend up to $20 \%$ of their time on educational and training activities. Within 60 days of their appointment, they will each develop an Individual Development Plan (IDP) of research and professional development (PD) milestones.

Establishing such a formal structure has been shown to support success, productivity and satisfaction (Davis 2005). Benefits of an IDP include:

- Empowering the student/post-doc to take ownership of his or her training

- Providing an open, direct dialogue about research and career goals

- Outlining concrete steps with timelines toward achieving those goals

- Helping to prepare for a career, both by developing core competencies and competencies specific to one's individual career goals

- Clarifying responsibilities and expectations for the mentee, research advisor and PD mentor

\section{Concept}

The IDP is a personal action plan, jointly agreed to by the mentee, research advisor, PD mentor, and IDP coordinator. It will include six core competencies: Research, Teaching \& Mentoring, Leadership, Oral \& Written Communication, Place \& Culture, and Career Development. For each competency, the IDP identifies milestones, as well as the training and experiences needed to achieve these milestones within a mutually agreed time frame. Each IDP is uniquely tailored to the needs of the individual. It is an evolving document that will be revisited throughout the appointment.

Setting milestones will help individuals to be more deliberate about their education and training experiences, and keep them on track. The best milestones are SMART

- $\quad$ specific (Is the milestone focused and unambiguous?)

- Measurable (Can you measure whether you have achieved the milestone?) 
- Actionable (Is there an action required on your part?)

- Realistic (Considering difficulty and timeline, is the milestone achievable?)

- Iimely (By when will you complete the milestone?)

\section{Preparing an IDP}

The graduate student or post-doc (mentee) will initiate this process with full participation by the research advisor and PD mentor. This involves a series of steps:

\begin{tabular}{|c|c|c|}
\hline & For graduate student/post-doc & For research advisor \& PD mentor \\
\hline $\begin{array}{l}\text { Step } 1 \\
\text { (within } 10 \text { days) }\end{array}$ & $\begin{array}{l}\text { - Complete a written self- } \\
\text { assessment (Form 1) }\end{array}$ & $\begin{array}{l}\text { Review mentee's self- } \\
\text { assessment and provide } \\
\text { feedback }\end{array}$ \\
\hline $\begin{array}{l}\text { Step } 2 \\
\text { (within } 20 \text { days) }\end{array}$ & \multicolumn{2}{|c|}{$\begin{array}{l}\text { - Learn about research, PD and career opportunities, and discuss } \\
\text { among mentee, research advisor and PD mentor }\end{array}$} \\
\hline $\begin{array}{l}\text { Step } 3 \\
\text { (within } 30 \text { days) }\end{array}$ & $\begin{array}{l}\text { - Draft an IDP (Form 2) and share } \\
\text { draft with advisor and mentor }\end{array}$ & $\begin{array}{l}\text { - Review draft IDP and suggest } \\
\text { revisions }\end{array}$ \\
\hline $\begin{array}{l}\text { Step } 4 \\
\text { (within } 40 \text { days) }\end{array}$ & $\begin{array}{l}\text { - Submit draft IDP (Form 2) to } \\
\text { IDP coordinator; schedule } \\
\text { appointment to review }\end{array}$ & $\begin{array}{l}\text { - Participate in review } \\
\text { meeting with mentee and } \\
\text { IDP coordinator (optional) }\end{array}$ \\
\hline $\begin{array}{l}\text { Step } 5 \\
\text { (within } 60 \text { days) }\end{array}$ & $\begin{array}{l}\text { - Finalize and submit IDP (Form } \\
\text { 2) and cover sheet (Form 3) to } \\
\text { IDP coordinator. Begin } \\
\text { implementation }\end{array}$ & $\begin{array}{l}\text { - Sign off on cover sheet } \\
\text { (Form 3) }\end{array}$ \\
\hline $\begin{array}{l}\text { Step } 6 \\
\text { Review IDP once } \\
\text { per semester } \\
\text { MAR } 30, \text { OCT } 30\end{array}$ & \multicolumn{2}{|c|}{$\begin{array}{l}\text { Schedule a meeting with research advisor, PD mentor and IDP } \\
\text { coordinator to review progress and outline future activities. Revise } \\
\text { IDP (Form 2) and resubmit to IDP coordinator. }\end{array}$} \\
\hline $\begin{array}{l}\text { Step } 7 \\
\text { Self-assess annually } \\
\text { MAR } 30 \text { or OCT } 30\end{array}$ & $\begin{array}{l}\text { - Re-do written self-assessment } \\
\text { (Form 1) }\end{array}$ & $\begin{array}{l}\text { Review mentee's self- } \\
\text { assessment and provide } \\
\text { feedback }\end{array}$ \\
\hline
\end{tabular}

IDP coordinator email: epscor.ed@gmail.com 


\section{Getting Started: A 'how to guide' to create your IDP}

\section{STEP 1 - Complete a written self-assessment}

- Conducting a self-assessment (Form 1) is the first step in developing your IDP. The self-assessment will allow you to craft a vision for your personal growth over the course of your graduate or post-doctoral career. You will re-take this selfassessment each April, so that you, your research advisor and PD mentor can reflect on the past year and revise your IDP as needed.

- Use the self-assessment as a tool to survey your current skills and abilities. Try to be realistic when identifying your strengths and defining the areas that need development. Ask your colleagues, family and friends what they see as your strengths, and areas where you may need to improve.

- This self-assessment focuses on six core competencies. For each competency, review the questions and respond in the space provided. Then, for each skill set listed on the bottom of the page, rate yourself on the scale provided. After you have completed the written self-assessment, share it with your research advisor and PD mentor and ask for their honest feedback.

\section{STEP 2 - Survey research, PD and career opportunities and discuss with research advisor and PD mentor}

- Within each core competency, identify and outline opportunities that interest you.

- Identify the skill sets you will need to develop, if any, to pursue these opportunities. How will you develop these skill sets?

- Set up a meeting with your research advisor and PD mentor to discuss the opportunities that you have identified, as well as opportunities that your advisor and PD mentor may have identified as being useful to you.

\section{STEPS 3 \& 4 - Draft your IDP (Form 2) and share with your advisor, PD mentor and IDP Coordinator}

A couple of important things to remember when starting to write your IDP:

- Your IDP is an evolving document that will be updated as often as needed.

- Start by identifying your personal long-term career goal

- Example 1: Become a tenure-track economics professor at a research intensive 
university

- Example 2: Conduct engineering research in a government lab that directly impacts the quality of water in Hawaii

- Example 3: Work for an environmental consulting firm on the US Mainland

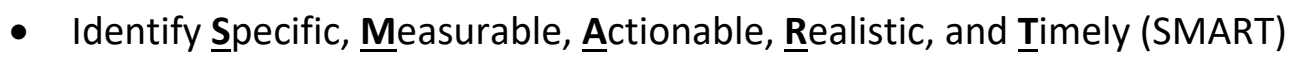
milestones that will help you achieve your long-term career goal. Record these on Form 2 (column 1).

- Think about what skills, strengths and experiences are needed to accomplish your milestones. Define approaches and strategies of how you will obtain and/or develop certain skills, strengths and experiences (column 2), and a timeframe (column 3).

- Include an output/outcome statement that can easily be measured, so you know whether you have met your goal (column 4). Think about what you will see, do or be when you accomplish this milestone. If it is difficult to state, then reframe the milestone to be more concrete, specific and actionable.

- Share your IDP draft with your research advisor and PD mentor, and receive constructive and honest feedback.

- Revise and submit your IDP to 'Ike Wai IDP coordinator.

- Set up a review meeting with the IDP coordinator to discuss your IDP revised draft. (Optional: Invite your research advisor and/or PD mentor to the meeting. Although their presence isn't required, it might be useful.)

- Finalize and obtain required signatures (Form 3)

\section{STEP 5 - Submit your finalized IDP to IDP coordinator and begin implementation}

- Email your final IDP (Form 2) and the cover sheet (Form 3) to the IDP coordinator, with copies to your advisor and PD mentor.

- Start implementing your IDP. 


\section{STEP 6 - Regular Review of Progress}

- Meet with your research advisor, PD mentor and IDP coordinator regularly. We require a meeting each semester, and encourage more frequent meetings.

- Revise and modify your IDP as necessary based on evolving goals and your discussions with your research advisor and PD mentor. Don't hesitate to ask for help if you feel you are not making the progress that you wish.

- Each April, electronically submit your revised IDP and revised self-assessment to the IDP coordinator, flagging any significant updates. Be sure to get the appropriate signatures before submitting.

\section{STEP 7 - Annual self-assessment}

- Re-do the written self-assessment each year. This will help you see where you have significantly progressed and where there is still room to grow. 


\section{Resources}

Self-assessment and planning your IDP

$\checkmark$ Science Careers: http://myidp.sciencecareers.org/

$\checkmark$ Fiske, P.S. (2001) Put Your Science to Work: The Take-Charge Career Guide for Scientists. American Geophysical Union

\section{Teaching \& Mentoring}

$\checkmark$ Advisor, Teacher, Role Model, Friend (1997) On being a Mentor to Students in Science and Engineering. National Academy Press

$\checkmark$ Carl Wieman Science Education Initiative: http://www.cwsei.ubc.ca/

$\checkmark$ Science Education Resource Center: http://serc.carleton.edu/index.html

\section{Leadership}

$\checkmark$ Linsky, M, Heifetz, R.E. (2002) Leadership on the Line: Staying Alive Through the Dangers of Leading. Harvard Business Review Press

$\checkmark$ Sapienza, A.M. (2004) Managing Scientists: Leadership Strategies in Scientific Research. Wiley-IEEE, Inc.

$\checkmark$ Myers, B. (2011) Take the Lead. Atria Paperback. Simon \& Shuster, Inc.

\section{Oral \& Written Communication}

$\checkmark$ Day, R. and Gastel, B. (2011) How to Write and Publish a Scientific Paper. Greenwood

$\checkmark$ Browning, B. (2008) Perfect Phrases for Writing Grant Proposals. Madison, Wisconsin: CWL Publishing Enterprises

$\checkmark$ Olson, R. (2009) Don't Be Such A Scientist. Island Press

\section{Place \& Culture}

$\checkmark$ Clark, J.R.K., Hawai'i Place Names (2002). University of Hawai'i Press

$\checkmark$ Morgan, J.R., Hawai'i: A Unique Geography (1996). Bess Press

$\checkmark$ Pukui, M.K., Elbert, S.H. (1986) Hawaiian Dictionary. University of Hawai'i Press

$\checkmark$ Sterling, E.P, Summers, C.C. (1978). Sites of O`ahu. Bernice Pauahi Bishop Museum

\section{Career Development}

$\checkmark$ Bolles, R.N. (2002) What Color is you Parachute? A Practical manual for JobHunters and Career-Changers. Ten Speed Press

$\checkmark$ Robbins-Roth, C. (2006) Alternative Careers in Science - Leaving the Ivory Tower. Elsevier

$\checkmark$ Careers in Science and Engineering (1996) A Student Planning Guide to Grad School and Beyond. National Academy Press 
1. Research (e.g., fieldwork, modeling, data visualization, translation)

\begin{tabular}{|l|l|l|l|}
\hline \multicolumn{1}{|c|}{ Milestones } & \multicolumn{1}{|c|}{ Approaches/Strategies } & \multicolumn{1}{c|}{ Deadline } & \multicolumn{1}{c|}{ Outputs/Outcomes } \\
\hline $\begin{array}{l}\text { Example: Answer the question “How does } \\
\text { water quality vary seasonally/temporally" }\end{array}$ & $\begin{array}{l}\text { Resample the same 5 DWS wells in } \\
\text { Hualalai in Mar, Aug \& Dec 2018 }\end{array}$ & $\begin{array}{l}\text { Dec 2018 (fieldwork) } \\
\text { Feb 2019 (analysis) }\end{array}$ & $\begin{array}{l}\text { GIS maps showing how water quality } \\
\text { varies at DWS wells between these 3 } \\
\text { time stamps }\end{array}$ \\
\hline & & & \\
\hline
\end{tabular}

2. Teaching \& Mentoring (e.g., teach or TA a class, mentor an undergraduate student)

\begin{tabular}{|l|l|l|l|}
\hline \multicolumn{1}{|c|}{ Milestones } & \multicolumn{1}{|c|}{ Approaches/Strategies } & Deadline & \multicolumn{1}{c|}{ Outputs/Outcomes } \\
\hline $\begin{array}{l}\text { Example: Teach a 3 credit class at a } \\
\text { Community College (CC) }\end{array}$ & $\begin{array}{l}\text { Contact Department Chairs at 3 CCs } \\
\text { \& ask about teaching opportunities }\end{array}$ & Spring 2019 & $\begin{array}{l}\text { Taught entry level class in xx at } \\
\text { Leeward CC during Spring 2019 }\end{array}$ \\
\hline & & & \\
\hline
\end{tabular}

3. Leadership (e.g., negotiation, strategic persuasion, collaboration)

\begin{tabular}{|l|l|l|l|}
\hline \multicolumn{1}{|c|}{ Milestones } & \multicolumn{1}{|c|}{ Approaches/Strategies } & \multicolumn{1}{c|}{ Deadline } & \multicolumn{1}{c|}{ Outputs/Outcomes } \\
\hline $\begin{array}{l}\text { Example: Attend a workshop focusing on } \\
\text { strategies to be a better negotiator }\end{array}$ & $\begin{array}{l}\text { Survey workshop opportunities on } \\
\text { developing negotiation skills } \\
\text { Fall 2018/Spring } \\
2019\end{array}$ & $\begin{array}{l}\text { Attended a workshop on } \\
\text { negotiation }\end{array}$ \\
\hline & & & \\
\hline
\end{tabular}


4. Oral \& Written Communication (e.g., peer-reviewed publications, grant proposals, blogs, presentations, media interviews)

\begin{tabular}{|l|l|l|l|}
\hline \multicolumn{1}{|c|}{ Milestones } & \multicolumn{1}{|c|}{ Approaches/Strategies } & \multicolumn{1}{c|}{ Deadline } & \multicolumn{1}{c|}{ Outputs/Outcomes } \\
\hline $\begin{array}{l}\text { Example: Submit NSF Graduate Research } \\
\text { Fellowship Program (GRFP) proposal }\end{array}$ & $\begin{array}{l}\text { Get examples of previous successful } \\
\text { applications from other students }\end{array}$ & October 23, 2018 & $\begin{array}{l}\text { Submitted proposal. Decision } \\
\text { expected spring 2019 }\end{array}$ \\
\hline & & & \\
\hline
\end{tabular}

\section{Place \& Culture}

\begin{tabular}{|l|l|l|l|}
\hline \multicolumn{1}{|c|}{ Milestones } & \multicolumn{1}{|c|}{ Approaches/Strategies } & Deadline & Outputs/Outcomes \\
\hline $\begin{array}{l}\text { Example: Learn to pronounce and spell all } \\
\text { Hawaiian words and place names in 'Ike } \\
\text { Wai proposal and core values document. }\end{array}$ & $\begin{array}{l}\text { Rords/place names. Ask Hawaiian } \\
\text { language grad students for training }\end{array}$ & December 2018 & \\
\hline & & & \\
\hline
\end{tabular}

6. Career Development (e.g., career exploration, networking, interview skills, CV writing, website development)

\begin{tabular}{|l|l|l|l|}
\hline \multicolumn{1}{|c|}{ Milestones } & \multicolumn{1}{|c|}{ Approaches/Strategies } & \multicolumn{1}{c|}{ Deadline } & \multicolumn{1}{c|}{ Outputs/Outcomes } \\
\hline $\begin{array}{l}\text { Example: Conduct 5 informational } \\
\text { interviews re: tenure-track economics } \\
\text { faculty positions (my career goal) }\end{array}$ & $\begin{array}{l}\text { Contact tenure-track economics } \\
\text { faculty at various institutions and } \\
\text { request interviews }\end{array}$ & $\begin{array}{l}\text { Jan-May 2019 (1 per } \\
\text { month) }\end{array}$ & $\begin{array}{l}\text { List of skill sets that I need to } \\
\text { develop to be competitive for this } \\
\text { job. Better understanding of job }\end{array}$ \\
\hline & & & \\
\hline
\end{tabular}




\section{IDP Cover Sheet for 'Ike Wai Graduate Students}

Name of graduate student:

Degree(s) you currently hold (e.g., BA - Economics):

Start date of graduate school at UH Manoa (e.g., Aug 2017):

Start date of 'Ike Wai graduate appointment (e.g., Feb 2018):

Current academic department (e.g., Hawaiian Language):

Current degree program: (if more than one, check the one you will get first)

$\_$MA _ $\quad$ MS _ $\quad$ PhD

_- Other/Notes:

Expected date of completing this degree (e.g., Dec 2020):

\section{IDP approved by:}

Graduate student (sign)

$\overline{\text { Research advisor (printed name) }}$

PD Mentor (printed name)

IDP Coordinator (printed name)
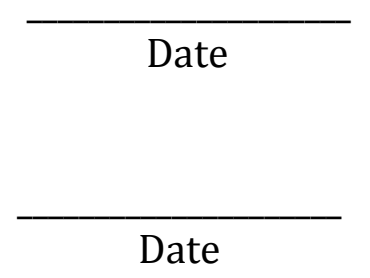

Research advisor (sign)

Date

PD Mentor (sign)

Date

\section{Email Forms 2 \& 3 to epscor.ed@gmail.com}

